\title{
La respuesta de la Villa y Corte de Madrid en el siglo XVIII ante la muerte del rey. Evolución de los códigos simbólicos de las Exequias Reales: Emblemas y alegorías
}

\author{
Denise LeÓN PÉREZ \\ Universidad de León \\ deniseleonperez@yahoo.es
}

\section{RESUMEN}

En el siglo XVIII, y tras la centralización sufrida con los Borbones, Madrid se pondrá a la cabeza en la consecución de las Exequias Reales, actos propagandísticos que aprovechaban el fallecimiento del monarca para mostrar la magnificencia del poder. En el presente análisis de las Honras nos hemos centrado en las semejanzas y dicotomías de los intereses propagandísticos y laudatorios de las celebraciones conmemoradas en la Villa y Corte de Madrid. Si la Corte utilizó estos actos como método de legitimación de la nueva casa reinante instaurada con Felipe V, la Villa buscó, en la conmemoración de estas honras, mostrar su magnificencia y su adhesión a la dinastía borbónica.

Palabras clave: exequias; fúnebre; Monarquía; simbolismo; propaganda; Barroco; emblemas; alegorías.

\section{The Answer of the Villa and Court of Madrid to the King's Death during the $18^{\text {th }}$ Century. The Evolution of the Symbolic Codes of the Royal Obsequies: Emblems and Allegories}

\begin{abstract}
During the $18^{\text {th }}$ century, after the arrival of the Bourbons, Madrid started being the most important centre where the Spanish Royal Obsequies were celebrated. In the current research about these acts, we focus on the political propaganda and the similarities and differences between the Court and Villa of Madrid. In this sense, the Court used these celebrations to legitimate the new dynasty, meanwhile the Villa looked for showing, in these acts, its splendour and its support for House of Bourbon.
\end{abstract}

Key words: obsequies; funeral; Monarchy; symbolism; propaganda; Baroque; emblems; allegories.

La representación institucional del monarca se configura como parte fundamental en los mecanismos de convencimiento de las masas durante el Antiguo Régimen. 
La propaganda apologética del poder emplea la cabeza visible de la institución para aglutinar, en torno a la idealización de su persona, los afectos del pueblo. En este sentido, a la hora de considerar las estrategias de manifestación pública del rey, debemos tener en cuenta dos ámbitos fundamentales, el de la etiqueta, que rige todos los actos ceremoniales en los que participa la Casa Real, y el de la configuración iconográfica de su persona, tanto en el ámbito plástico, como en el literario. Todos estos elementos confluyen en el aparato artístico e ideológico de los funerales simbólicos o Exequias Reales celebrados en todos los reinos Hispanos, así como en Italia y los virreinatos americanos.

Antes de centrarnos en el estudio de las honras en la Villa y Corte de Madrid durante el siglo XVIII, resulta necesario hacer una serie de puntualizaciones sobre los cambios generados al advenimiento de la nueva dinastía borbónica a España, inaugurada por Felipe V. En primer lugar, debemos destacar cómo la relación entre el pueblo y el rey va a variar sustancialmente a medida que avanza el siglo. Se va a impulsar un absolutismo ilustrado, de influencia francesa, donde ya no se habla de nación, sino de Estado. La relación con el monarca entra en una especie de servilismo y su imagen comienza a secularizarse. Este hecho se acentúa durante la segunda mitad del siglo XVIII, donde la mentalidad ilustrada reniega de la teoría por la cual la divinidad delegaría el poder directamente en la figura del rey. Es por ello, que la monarquía absoluta no buscará su justificación en los aspectos espirituales. Asímismo, la adhesión del pueblo a la dinastía borbónica no es la misma que existía con los Austria. Y es que durante esta centuria asistimos a la despersonalización de la monarquía, donde el rey se ha de concebir conjuntamente con sus ministros, tal y como se reconoce en los reinados de la segunda mitad del siglo, con Fernando VI y Carlos III. Por lo tanto, en este periodo vamos a observar una evolución desde un gobierno absolutista y personalista de origen divino hacia un estado impersonal secularizado, cuyo desarrollo se va a ver reflejado, tanto en el protocolo, como en los programas iconográficos promovidos.

Una vez trazadas brevemente las consideraciones fundamentales en torno a la evolución del poder monárquico, atenderemos al entorno geográfico madrileño. En el siglo XVIII, y tras la centralización sufrida con los Borbón, Madrid se pondrá a la cabeza en la consecución de las Exequias Reales. En cuanto a las ceremonias acaecidas en este siglo, es aconsejable su catalogación en base a tres periodos. Durante el primero, que se corresponde con el reinado de Felipe $\mathrm{V}$, tuvieron lugar las honras de Luis de Borbón (1711), Luis de Borgoña y María Adelaida de Saboya (1712), María Luisa Gabriela de Saboya (1714), Carlos, Duque de Berry (1714), Luis XIV (1716), Luis I (1725), Francisco Farnesio (1727) y Víctor Amadeo II de Saboya (1732).

En el segundo periodo, correspondiente a los trece años en los que se mantuvo en el trono Fernando VI, se festejaron los funerales simbólicos en honor de su padre, Felipe V (1746) y su familia política, Juan V de Portugal (1751) y de Mariana Josefa de Portugal (1754). En esta época también se habrían de solemnizar las exequias en honor de la reina Bárbara de Braganza, fallecida en 1758. No obstante, carecemos de datos que atestigüen su realización, a excepción de un grabado ilustrativo del túmulo diseñado por Sacchetti y que debía haberse alzado en el templo de la Encarnación. 
El tercer periodo es el del reinado de Carlos III, en el que observamos la carencia de datos relativos a los ceremoniales que deberían haber tenido lugar en honor de su hermanastro Fernando VI fallecido en 1759, su esposa María Amalia de Sajonia (1760) y su madre, Isabel de Farnesio (1766). Este silencio documental nos revela que, de haberse llevado a cabo estos actos, carecieron de la proyección pública de las ceremonias anteriores. Otra de las teorías acerca de la ausencia de noticias acerca de estas honras es que finalmente no se llevaran a cabo, ya que dentro del gobierno de Carlos III estos protocolos ceremoniales habrían perdido su valor político. Pero de ser así, no se entendería como en 1789 se ejecutaron las exequias en honor de este último, siguiendo el protocolo y la organización tradicional.

Tras este breve resumen de las exequias cortesanas del siglo XVIII, observamos cómo las honras no están reservadas únicamente a los monarcas hispanos, sino que también fueron solemnizados los actos en honor de príncipes y reyes extranjeros. Recogiendo los datos acerca de estos últimos, podemos plantear el mapa político de las alianzas de cada periodo. Felipe V, nacido en Versalles, promovió la concesión de honras en honor de su padre, El Gran Delfín, sus hermanos, Luis de Borgoña y Carlos Duque de Berry, y su abuelo Luis XIV. Así mismo, observamos la existencia de actos para conmemorar la muerte de Víctor Amadeo de Saboya, padre de su primera esposa, y Francisco Farnesio, tío de su segunda esposa, Isabel de Farnesio. Durante el reinado de Fernando VI, serán los monarcas lusos los que reciban las solemnidades debido al origen portugués de la reina consorte; Bárbara de Braganza. Desgraciadamente, y como ya referimos más arriba, carecemos de datos relativos a las posibles ceremonias realizadas durante el reinado de Carlos III.

Centrando nuestra mirada en el ámbito municipal, en el siglo XVIII, la Villa de Madrid, no sin un gran esfuerzo económico, intentará emular la grandilocuencia de las celebraciones cortesanas. Para ello llevará a cabo fastuosas ceremonias públicas con ocasión de las entradas reales, los nacimientos, las coronaciones y las exequias. Durante el reinado de Felipe V, la Villa celebró cinco exequias reales paralelamente a las de la Corte, y llegó a organizar otras dos, las de Francisco Farnesio y Víctor Amadeo de Saboya, las cuales finalmente no se ejecutaron. Esta continuidad ininterrumpida en la organización de honras fúnebres del primer tercio del siglo no se observa en la centuria anterior, lo que es indicativo del intento, por parte del municipio, de mostrar su adhesión a la nueva dinastía. Durante el reinado de Fernando VI observamos esa continuidad celebrativa en la conmemoración de los actos en honor de Felipe V y los monarcas portugueses, Juan V (1751) y Mariana de Portugal (1754). A partir de este momento y hasta las exequias de Carlos III en 1789, paralelamente a lo que ocurre en la Corte, desconocemos la existencia de ningún otro acto conmemorativo fúnebre.

Tras definir los aspectos fundamentales del contexto geográfico y político, a continuación, pasamos a desglosar los aspectos constitutivos de los actos. Para ello atenderemos a la estética del arte efímero, a la disolución de los conjuntos emblemáticos a medida que avanza el siglo XIX y, finalmente, a los diferentes niveles de comunicación y la evolución de sus modelos de codificación simbólica. 


\section{La efímera materialidad}

En el marco de la plástica, y centrándonos en los conjuntos efímeros, resulta de vital interés realizar un breve recorrido en torno a los túmulos que representaban, de forma simbólica, la presencia del difunto ${ }^{1}$. Estas obras arquitectónicas, mayoritariamente barrocas en su concepción, parten de modelos estructurales herederos de los baldaquinos para incorporar en su discurso, al final de la centuria, construcciones monumentales conmemorativas como los obeliscos. Iniciando nuestro estudio por las obras efímeras realizadas durante el reinado de Felipe V, debemos destacar la labor de Teodoro Ardemans, cuyo recorrido artístico ha sido analizado en los trabajos de Beatriz Blasco Esquivias ${ }^{2}$. No consideramos que sea necesario desarrollar aquí la amplia producción de Ardemans, pero sí anotar aquellos aspectos que se relacionan con su actividad en las celebraciones de exequias. La importancia de este arquitecto pasa por los numerosos cargos que ostentó. Fue Maestro Mayor de las Catedrales de Granada y Toledo, Maestro Mayor de la Villa, Maestro Mayor de Obras Reales, Pintor de Cámara del Rey y Fontanero y Veedor Mayor de Obras Reales. A parte de su actividad práctica, nos ha legado su obra Declaración y extensión, sobre las ordenanzas, en la que expone sus ideas acerca de la arquitectura y la defensa del liberalismo de este $a^{2}{ }^{3}$. Antiguo colaborador de José del Olmo, su irrupción en el diseño de las obras fúnebres se remonta a 1700, con motivo de la celebración municipal de las honras en honor a Carlos $\mathrm{II}^{4}$. Al año siguiente, participará en el diseño del aparato artístico para la entrada de Felipe V en Madrid, el 14 de abril, en el que mostró su más que cualificación para la configuración de los decorados efímeros 5 . Para esta celebración,

1 SOTO CABA, Victoria, Catafalcos reales del Barroco Español. Un estudio de arquitectura efímera, Madrid, UNED, 1991, pp. 249 y ss; Idem, "La configuración de un modelo. Los catafalcos madrileños durante el reinado de Felipe V", en Espacio, Tiempo y Forma, serie VII, tomo 2, 1989, pp. 169-195; BLASCO ESQUIVIAS, Beatriz, "Túmulos de Teodoro Ardemans durante el reinado de Felipe V", en Cuadernos de arte e iconografía, tomo V, ${ }^{\circ}$ 9, 1992, pp. 157-180. Centrándose en los aspectos, ya no solo estéticos, sino también simbólicos y literarios, encontramos la obra de LEÓN PEREZ, Denise, Las Exequias Reales en Madrid durante el primer tercio del siglo XVIII: Corte y Villa, León, Universidad de León, 2010.

2 BLASCO ESQUIVIAS, Beatriz, Teodoro Ardemans y su entorno en el cambio de siglo (1661-1761). Aspectos de la arquitectura y el urbanismo madrileños de Felipe II a Carlos III, Madrid, Universidad Complutense de Madrid, 1991. De esta misma autora encontramos un pormenorizado estudio acerca de la formación del arquitecto en: BLASCO ESQUIVIAS, Beatriz, "Una biblioteca Modélica. La formación libresca de Teodoro Ardemans (I)", en Ars Longa, n 5, 1994, pp. 73-97. Para los diseños tumulares llevados a cabo por el arquitecto contamos con el artículo: BLASCO ESQUIVIAS, Beatriz (1992), op. cit.

3 Declaración y extensión, sobre las ordenanzas, que escribió Juan de Torija...Francisco del Hierro, Madrid, 1719. En 1992 Blasco Esquivias publicó una edición facsímil, incluida en el primer tomo de su obra Arquitectura y urbanismo en las Ordenanzas de Teodoro Ardemans para Madrid, Ayuntamiento de Madrid.

4 Esta obra había sido atribuida por la historiografía tradicional a José Benito de Churriguera, no obstante, y tras el análisis iconográfico llevado a cabo por María Adelaida Allo, se pudo comprobar que esta obra no se había trazado para las exequias de María Luisa de Borbón, como venía considerándose, sino para un monarca: Carlos II. En: Exequias de la Casa de Austria en España, Italia e Hispanoamérica, Universidad de Zaragoza, (ed. microfichas), 1992, vol. I, pp. 225-270, 770 y ss.

5 BLASCO ESQUIVIAS, Beatriz, "Noticias sobre el Monte Parnaso erigido en Madrid para celebrar la entrada de Felipe V, en 1701", en Reales Sitios, Revista del Patrimonio Nacional, $\mathrm{n}^{\circ}$ 115, primer trimestre de 1993, pp. 25-32; ZAPATA FERNÁNDEZ DE LA HOZ, Teresa, "Proyecto y Participación de Teodoro Ardemans en la entrada pública en Madrid de Felipe V", en Archivo Español de Arte, no 255, 1991, pp. 361-372. El diseño de este conjunto puede ser consultado en los siguientes catálogos: El Antiguo Madrid, 
Ardemans realizó un arco del triunfo, dos galerías de arquillos que se habían de situar a ambos lados de la calle que llevaba del palacio del Buen Retiro a la Torrecilla del Prado, un Monte Parnaso frente al oratorio del Espíritu Santo, dos carros para comediantes y un castillo de fuegos artificiales para la plaza del Alcázar.

Centrándonos en sus catafalcos, éstos parten de la tipología inaugurada por José Benito Churriguera en 1689 para el túmulo de María Luisa de Orleans. Tomando como base este modelo, Ardemans llega a nuevas soluciones monumentales, pero sin alejarse del barroco, no ya tanto decorativo, como estructural. Dentro del aspecto decorativo, no podemos obviar la aportación del álbum de grabados de Fray Matías de Irala. Aunque la edición princeps de la obra Método Sucinto i Compendioso no se publica hasta 1731 , los diseños de Irala habrían sido difundidos con anterioridad, sirviendo como modelos ornamentales en estas obras efímeras ${ }^{6}$.

Iniciando nuestro análisis por las construcciones cortesanas de este artista, debemos destacar como, a partir de 1711, el encargo de las obras tumulares en la Corte se va a hacer privativo del Maestro Mayor que, por aquel entonces, era el propio Teodoro Ardemans ${ }^{7}$ (fig. 1). Sus primeras trazas, en 1711 y 1712, están adscritas todavía a un "barroco local", mientras que en los túmulos para las exequias de María Luisa Gabriela de Saboya (1714) y Luis XIV (1716), se observa un giro hacia la estética del "barroco internacional". Pero Ardemans volverá hacia el casticismo en su último túmulo, levantado en honor de Luis I (1725). Antes de continuar, resultar necesario puntualizar el uso del término de barroco local o castizo, que no es otro que el de diferenciar la tradición estética propiamente hispana, de las corrientes foráneas que irrumpen en el periodo.

A pesar de esta evolución, no obstante, en las construcciones de este arquitecto se van a establecer una serie de elementos estructurales que se mantendrán inamovibles en toda su obra. Son catafalcos de planta cuadrada, a excepción del túmulo cuadrangular de los Delfines (1712) que albergaba en su interior dos simulacros de tumba. Los túmulos se disponían sobre altos zócalos en los que se abrían cuatro escalinatas de acceso al interior. Los ángulos del primer cuerpo se articulaban mediante columnas exentas, consiguiendo, de esta manera, el aligeramiento de la estructura. La organización ascensional se amplificaba mediante la superposición de cuerpos rematados por elevadas composiciones ornamentales. Como buen dibujante que era, Ardemans se encargó de realizar los dibujos que el grabador llevaría a estampación

\footnotetext{
Madrid, 1926, nº 1386; Utopía y realidad en la Arquitectura, Madrid, 1985, nº 446 y Catálogo de Dibujos de Arquitectura y Ornamentación de la Biblioteca Nacional, Siglos XVI y XVII, Madrid, 1991, nº 63.

6 SOTO CABA, Vitoria (1991), op. cit., p. 277. El tratado de Fray Matías de Irala se publica en 1731 con el título Método Sucinto i Compendioso de cinco simetrías a los cinco órdenes de arquitectura. Dedícalas al Serenísimo Príncipe de Asturias D. Fernando N.S. Que Dios prospere.

7 El Maestro Mayor del Alcázar de la Corte y Casas Reales de su entorno, fue un oficio real instaurado ya desde el siglo XVI y que se mantuvo hasta su extinción, durante el reinado de Carlos III. El nombramiento de Teodoro Ardemans se produjo en 1702 tras la muerte de Juan del Olmo. La asignación del cargo se realizaba a través de un concurso de acceso libre, en el que se llevaba a cabo una evaluación de méritos. Tras la muerte de Ardemans, en 1727, y mediante promoción interna, el cargo será adjudicado al Aparejador Primero Juan Román. BLASCO ESQUIVIAS, Beatriz, "El Maestro Mayor de Obras Reales en el siglo XVIII, sus Aparejadores y su Ayuda de Trazas", en El Real Sitio de Aranjuez y el Arte Cortesano del Siglo XVIII, (Aranjuez, Abril-Mayo 1987), Madrid, 1987, pp. 271-286.
} 


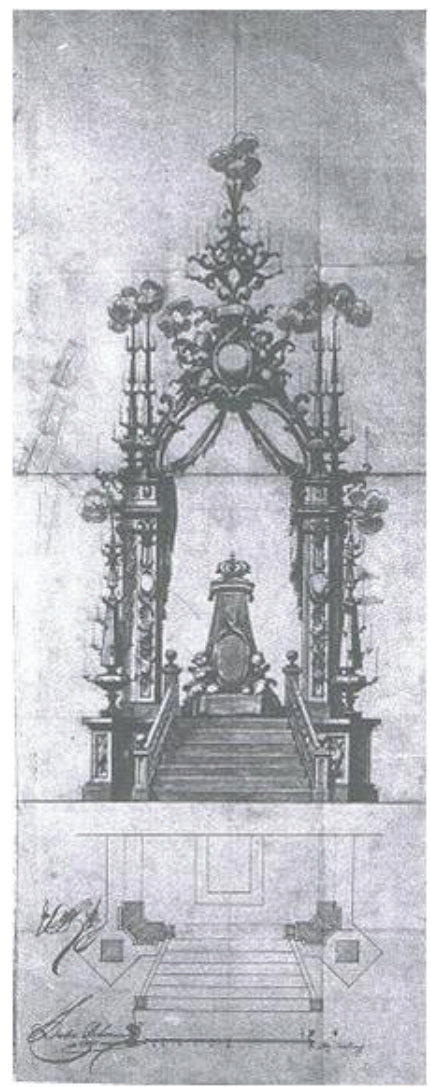

Fig. 1. Teodoro Ardemans. Traza para el túmulo para las honras municipales de Luis de Borbón. 1711.

para ser incluidos en los Libros de Exequias publicados con motivo de las ceremonias, y que se configuran como una de las fuentes documentales más importantes de nuestro estudio. En estos grabados, podemos comprobar cómo la ornamentación va evolucionando hacia composiciones menos abigarradas, más solemnes. Un ejemplo lo encontramos en la representación de las esculturas femeninas de las virtudes, que solían acompañar el túmulo, en las cuales se puede reconocer un aire clasicista de influencia italiana. Su labor en la Corte será retomada a su muerte por Juan Román, que realizó, en 1727, el túmulo para las exequias de Francisco Farnesio, obra que responde a la configuración, tanto arquitectónica, como alegórica, inaugurada por Teodoro Ardemans ${ }^{8}$. En cuanto a la valoración estilística, como ya señaló Victoria Soto Caba, no será hasta la irrupción de Sacchetti, en los años cuarenta, cuando las

8 Juan Román había ocupado el puesto de aparejador de Obras Reales desde 1715. Por la Real Cédula el 11 de junio de 1727, será nombrado Maestro Mayor. Vid. LLAGUNO Y AMIROLA, Eugenio, Noticia de los arquitectos y arquitectura en España desde su restauración, Madrid, Imprenta Real, 1829, tomo IV, p. 113. 
estructuras de los túmulos se inserten plenamente en la corriente del barroco internacional $^{9}$. Y es que los cambios que se producen en la arquitectura fúnebre durante las primeras décadas no responden al conjunto estructural, sino que afectan únicamente a los aspectos decorativos.

Atendiendo a las construcciones municipales de este periodo, el Ayuntamiento y la Corte compartirán el mismo tracista, el propio Ardemans, en las exequias de 1711 y 1714. Para las restantes construcciones de 1712, 1716, 1725, 1727 y 1733, el arquitecto encargado de las trazas fue Pedro de Ribera que, no obstante, contó con la supervisión del propio Ardemans ${ }^{10}$. De las construcciones de Ribera, y sin entrar en aspectos concretos de cada una de ellas, debemos destacar su adscripción a la tradición del barroco hispano. Sus obras participaban de un mayor juego decorativo y efectista aunque, en ocasiones, como ocurrió en las exequias municipales de Luis XIV, su obra adquiere una mayor sobriedad arquitectónica, posiblemente por influencia de Ardemans ${ }^{11}$.

A partir de 1746, con motivo de las honras de Felipe V, Juan Bautista Sacchetti se hará con la batuta compositiva de los diseños tumulares, tanto en la Corte, como en la Villa $^{12}$. Este arquitecto turinés llegó el 6 de septiembre de 1736 para ponerse al frente de los trabajos en el palacio de la Granja sustituyendo a Juvarra ${ }^{13}$. Su labor se ampliará al Nuevo Palacio Real, proyectado sobre el solar del antiguo Alcázar de Madrid. La principal aportación de Sacchetti a esta obra fue la reducción del proyecto de Juvarra a una cuarta parte, eliminando la horizontalidad que había planteado su maestro. Dos días después de que la Corte se instalara definitivamente en el nuevo edificio regio, el 1 de diciembre de 1764, Sacchetti fallece a la edad de 74 años, siendo enterrado en la Iglesia Parroquial de San Juan Bautista, ahora desaparecida ${ }^{14}$. Entre los muchos cargos que ostentó fue Director de la Real Academia de San Fernando y Maestro Mayor de la Corte y de la Villa.

Centrando nuestra atención en sus diseños arquitectónicos para las honras fúnebres, debemos destacar sus primeras aportaciones italianas, que ya fueron estudiadas por Bottineau ${ }^{15}$. En septiembre de 1722 participó en la construcción fúnebre de las

\footnotetext{
9 SOTO CABA, Victoria (1991), op. cit., pp. 285 y ss.

10 Un ejemplo de esta supervisión por parte del Maestro Mayor lo encontramos en el Pliego de Condiciones de la construcción municipal de 1712, donde a las condiciones de Ribera se le añaden otras hechas por Ardemans. A.S.A., Secretaría, 2-351-5.

11 VERDÚ RUIZ, Matilde, El arquitecto Pedro de Ribera, Madrid, Instituto de Estudios Madrileños, 1999.

12 SANCHO GASPAR, José Luis, "Sacchetti y los salones del Palacio Real de Madrid", en Reales Sitios: Revista del Patrimonio Nacional, nº 96, 1988, pp. 37-44; GONZÁLEZ SERRANO, Ascensión, Juan Bautista Sacchetti, arquitecto mayor del Rey y Maestro Mayor de la villa de Madrid y de sus fuentes, (de 1736-1764), tesis inédita, Universidad Complutense de Madrid, 2001.

13 ORTEGA VIDAL, Javier y SANCHO GASPAR, José Luis, "Entre Juvarra y Sacchetti: El Emblema oriental de la Granja de San Ildefonso", en Reales Sitios. Revista del Patrimonio Nacional, n 119, 1994, pp. $55-64$

14 PlaZA SANTIAGO, Francisco Javier de la, "El testamento de Sacchetti", en Boletín del Seminario de Estudios de Arte y Arqueología, no 38, 1972, pp. 39-47; Idem, "Para la biografía de Giovanni Battista Sacchetti", en Boletín del Seminario de Estudios de Arte y Arqueología, no 36, 1970, pp. 525-528.

15 BOTTINEAU, Yves, El arte cortesano en la España de Felipe V, Madrid, Fundación Universitaria Española, 1986, pp. 582 y ss.
} 
exequias de la princesa Este-Cargnan en la catedral de Turín, en 1728 en las de la reina Anne de Orleáns, en las de Víctor Amadeo II en 1732 y, en 1735, en las de la reina Polixena. Sus primeros proyectos para las exequias hispanas datarían de 1740, con motivo del fallecimiento de Mariana de Neoburgo, viuda de Carlos II, aunque esta ceremonia nunca se llevó a cabo. Desde ese instante pasó a ser el encargado de los diseños tumulares, tanto de la Corte, como de la Villa, de las exequias de Felipe V (1746), Juan V de Portugal (1751) y Mariana Josefa (1754).

Debido a su formación y a la filiación de sus influencias, suponían un avance hacia el barroco internacional, gusto imperante en Europa. En sus conjuntos arquitectónicos se observa una evolución manifiesta frente al barroco casticista patrocinado por Pedro de Ribera en el municipio y las obras de Teodoro Ardemans y Juan Román en la Corte. Para las honras cortesanas de Felipe V, el arquitecto diseñó un túmulo basado en el templete clásico que, no obstante, mantenía el efectismo barroco de estas construcciones. Pero a pesar de esta evolución estética, con motivo de las exequias en honor de Juan V (1751), una vez Fernando VI hubo analizado el primer diseño del túmulo realizado por el arquitecto italiano, lo rechazó por considerarlo poco majestuoso y le instó a repetir los esquemas barrocos, como los desarrollados por Teodoro Ardemans en las primeras décadas del siglo ${ }^{16}$. La causa de la inclinación de Fernando VI no es tanto de gusto personal, sino que es fruto de una necesidad comunicativa debido a la plena codificación de los modelos anteriores, aspecto que someterá las creaciones de este arquitecto en la Corte.

Con esta decisión se rompía con la evolución del catafalco cortesano iniciada por Sacchetti cinco años antes. En 1754 lleva a cabo la construcción del túmulo para las exequias cortesanas de Mariana Josefa cuya factura, desgraciadamente, desconocemos. Finalmente, en 1758, y a pesar de que carecemos de datos que confirmen la celebración de las honras en honor de Bárbara de Braganza, sale a la luz un grabado de Juan Bernabé Palomino reproduciendo el dibujo del túmulo diseñado por Sacchetti para las exequias de la reina en el monasterio de la Encarnación ${ }^{17}$. La obra tumular de Sacchetti se configura a partir de un zócalo, de planta octogonal, donde se abre un cuerpo de escaleras para acceder al primer cuerpo donde reposa el simulacro de tumba. Podemos aventurar que se trata de un modelo apegado a los diseños que el mismo autor había realizado para Juan V y María Josefa de Austria bajo la atenta mirada del monarca, para el que primaba el ejemplo de las construcciones realizadas a principios de siglo por encima de los nuevos modelos clasicistas.

Durante este mismo periodo, y como ya hemos aludido anteriormente, Sacchetti será también el encargado de la configuración de los túmulos municipales de las exequias de 1746, 1751 y 1754. Para las honras en honor de Felipe V, carecemos de imagen que nos ilustre su configuración, sin embargo, la proliferación de figuras alegóricas macabras referidas en el libro de exequias y el expediente documental, nos recuerda el diseño del túmulo trazado para las exequias de Víctor Amadeo II de Saboya por Pedro de Ribera en 1733. De estas últimas sabemos, gracias a la documentación

16 Desgraciadamente se desconoce la existencia de una imagen ilustrativa de la obra efímera.

17 PALOMINO, Juan Bernabé, Túmulo de Bárbara de Braganza erigido en la iglesia del convento de la Encarnación de Madrid, Madrid, 1758, Biblioteca Nacional de España, INVENT/14783. 


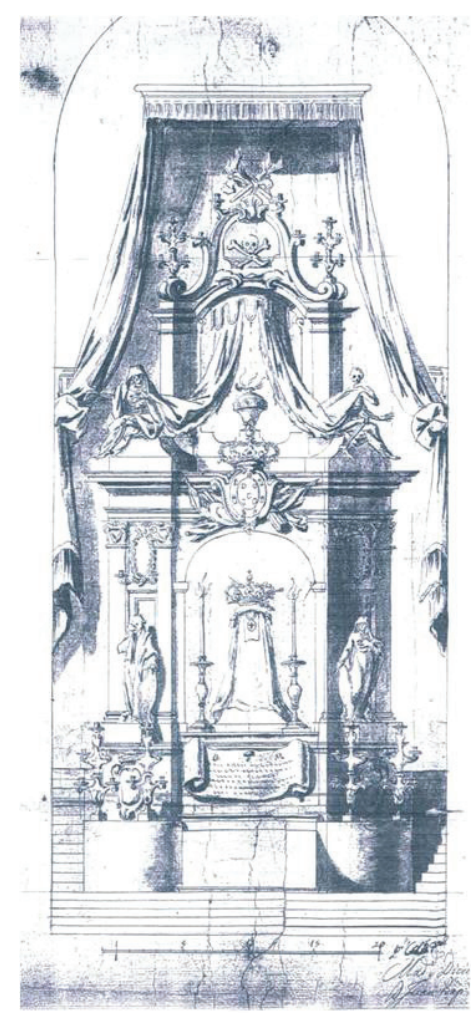

Fig. 2. Giovanni Battista Sacchetti. Traza para el túmulo para las honras municipales de Juan V de Portugal. 1751.

contenida en el expediente que, aunque finalmente no se llevó a cabo la ceremonia municipal en honor del Rey de Cerdeña, las esculturas fueron finalizadas y almacenadas para futuros usos. Es por ello que, teniendo en cuenta que las ceremonias de Felipe V son las primeras que se realizan desde 1733 en el Ayuntamiento, no nos parece improbable la reutilización de estas figuras escultóricas por parte de Sacchetti.

En 1751, Sacchetti realiza el diseño del túmulo para las honras de Juan V de Portugal (fig. 2). La obra, en forma de ochavo, se encontraba inscrita dentro de la corriente clasicista, posiblemente cercano al modelo que pudo haber presentado a Fernando VI este artista con motivo de las honras cortesanas del propio Juan V, y que fuera rechazado por su poca monumentalidad. Sin embargo, la composición municipal, a diferencia del encargo cortesano, no se hallaba supeditada al gusto institucional. Esto permitió a Sacchetti realizar una obra más cercana al barroco clasicista italiano ${ }^{18}$. Finalmente, en 1754 diseñará el túmulo municipal de las honras de Mariana Josefa, del que podemos destacar su amplia profusión de alegorías aunque carecemos de un grabado o dibujo ilustrativo que nos permita conocer su estructura. Así mismo, tam-

18 SOTO CABA, Victoria (1991), op. cit., p. 321. 


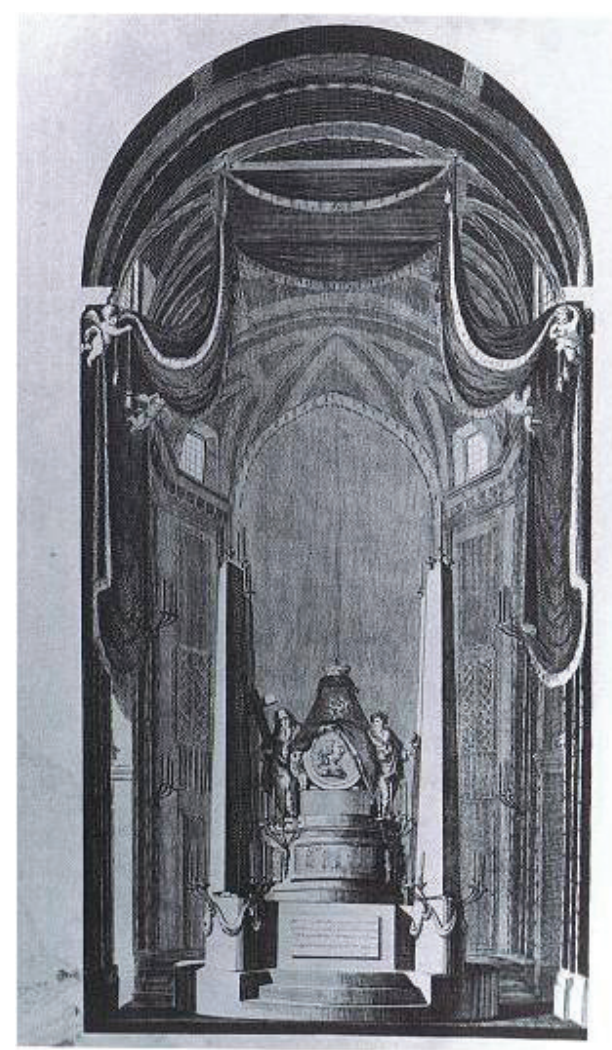

Fig. 3. Juan de Villanueva. Traza para el túmulo para las horas municipales de Carlos III. 1789.

bién desconocemos los datos concernientes a los diseños que hubiese podido realizar para las ceremonias en honor de Bárbara de Braganza (1758) en el municipio y de Fernando VI (1759) y María Amalia de Sajonia (1760), tanto para la Corte, como para la Villa. Estos actos serían coincidentes con los últimos años de profesión del artista, que fallece en 1764.

A partir de 1789, con motivo de las honras celebradas en honor de Carlos III, se inaugura, en algunos centros españoles, un nuevo modelo de túmulo, de carácter monumental, que sustituye la articulación barroca en diferentes cuerpos. En las exequias cortesanas de este monarca el maestro encargado del ornato fue Manuel Rodríguez, sobrino de Ventura Rodríguez ${ }^{19}$. La elección resulta extraña dada la preferencia del monarca por la estética promovida por Francesco Sabatini, más acorde con las co-

19 Manuel Martín Rodríguez fue el heredero de los bienes de su tío, incluyendo su imponente biblioteca cuyo análisis da cuenta de la formación e influencias de ambos arquitectos: BLANCO MOZO, Juan Luis, "La cultura de Ventura Rodríguez y la biblioteca de su sobrino Manuel Martín Rodríguez", en Anuario del Departamento de Historia y Teoría del Arte, n 7-8, 1995-1996, pp. 181-222. 
rrientes arquitectónicas europeas ${ }^{20}$. No obstante, este último aparece firmando gran parte de los documentos, lo que nos informa que el maestro italiano supervisó las construcciones de Rodríguez. Desgraciadamente, se desconoce la existencia del libro oficial de las exequias cortesanas de Carlos III, así como el grabado del túmulo, el cual nos permitiría arrojar más luz sobre la lenta asimilación de los nuevos postulados por parte de la Corte madrileña. Soto Caba ha definido la obra tumular de Manuel Rodríguez como un modelo romano basado en presupuestos aún barrocos, y que entra en relación con el realizado por Panini en Roma para las exequias de Fernando $\mathrm{VI}^{21}$. Remitiendo a la descripción existente en el expediente documental, la obra de Rodríguez parte aún de fórmulas barrocas revestidas de motivos clasicistas.

En este caso será el Ayuntamiento el que se ponga a la cabeza en la asimilación de los modelos neoclásicos. La obra del capelardente, diseñada por Juan de Villanueva, posee un carácter más equilibrado que la obra que trazó Manuel Rodríguez para las exequias cortesanas ${ }^{22}$. En esta construcción se observa la aplicación de los nuevos postulados arquitectónicos, alejándose de la tradición constructiva barroca a través del empleo de un conjunto monumental configurado por una urna y cuatro obeliscos alzados sobre un zócalo circular (fig. 3) ${ }^{23}$.

Estos túmulos o construcciones efímeras, lejos de desaparecer durante el siglo XIX, se adaptarán a las tendencias historicistas, retomando grandes hitos arquitectónicos. Ejemplo de ello es el neomedievalismo que observamos en el túmulo de las exequias cortesanas de Fernando VII. Estas ceremonias tuvieron lugar los días 9 y 10 de mayo de 1834 en el templo de San Jerónimo. Para este evento, el arquitecto Valentín Cardereda levantará un túmulo de carácter neogótico, en correlación con la estética del edificio que le sirve de escenario (fig. 4) ${ }^{24}$.

20 SOTO CABA, Victoria, "Los catafalcos de Carlos III: entre la influencia neoclásica y la herencia del barroco", en Fragmentos, no 12-13-14, 1988, pp. 129-143.

21 Relación de las exequias que a la majestad del rey católico d. Fernando VI. se hicieron en la Real iglesia de Santiago de los españoles de Roma siendo ministro encargado de los reales negocios di S.M. el eño y rmo señor fr. d. Joachim Portocarrero, cardenal obispo sabinense, Roma, Imprenta de los Hermanos Joachin y Juan José Salvioni, 1760, Archivo de la Real Academia de Bellas Artes, B-838.

22 Sobre esta obra véase: SOTO CABA, Victoria (1991), op. cit., p. 341 y ss.

23 VILLANUEVA, Juan, "Explicación del catafalco erigido por el Arquitecto de S.M. y mayor de Madrid D. Juan de Villanueva", en ESPINOSA, F. Manuel de, Oración fúnebre, que en las solemnes exequias que hizo la muy noble, muy leal, imperial y coronada villa de Madrid... a la dulce memoria de su difunto rey el señor Don Carlos III, Madrid, Imprenta de la viuda de Ibarra, 1789. La villa encargó al propio Juan de Villanueva un dibujo del conjunto para realizar un grabado e incluirlo en la edición. A.S.A., Secretaría, 2-355-2. Papel del día 6 de abril de 1789. El grabado lleva la firma de J.B. Rubio.

24 Perspectiva del Catafalco erigido en la Iglesia del Real Monasterio de San Gerónimo de esta Corte, por disposición de la Diputación permanente de la Grande de España, que celebró la clase en la misma por el alma del Rey Nro. Sor. Don Fernando VII (q.e.g.e.) el día 6 de octubre de 1834..., Valentín Carderera lo inventó y dirigió; $F$. Blanchard lo dibujó y litografió, Estampado en el Real Establecimiento Litográfico de Madrid, 1834, R.B. Sig. arch3/caj/22 (42). Vid. PANADERO PEROPADRE, Nieves, Los estilos medievales en la arquitectura madrileña del siglo XIX (1780-1868), Tesis Doctoral, Universidad Complutense, 1992, tomo II, pp. 682 y ss. La autora de esta tesis puso en relación la obra neogótica de Cardereda con las tumbas escalígeras de Verona y los monumentos sepulcrales de Santes Creus que el arquitecto había conocido durante su estudio de los Panteones Reales. 


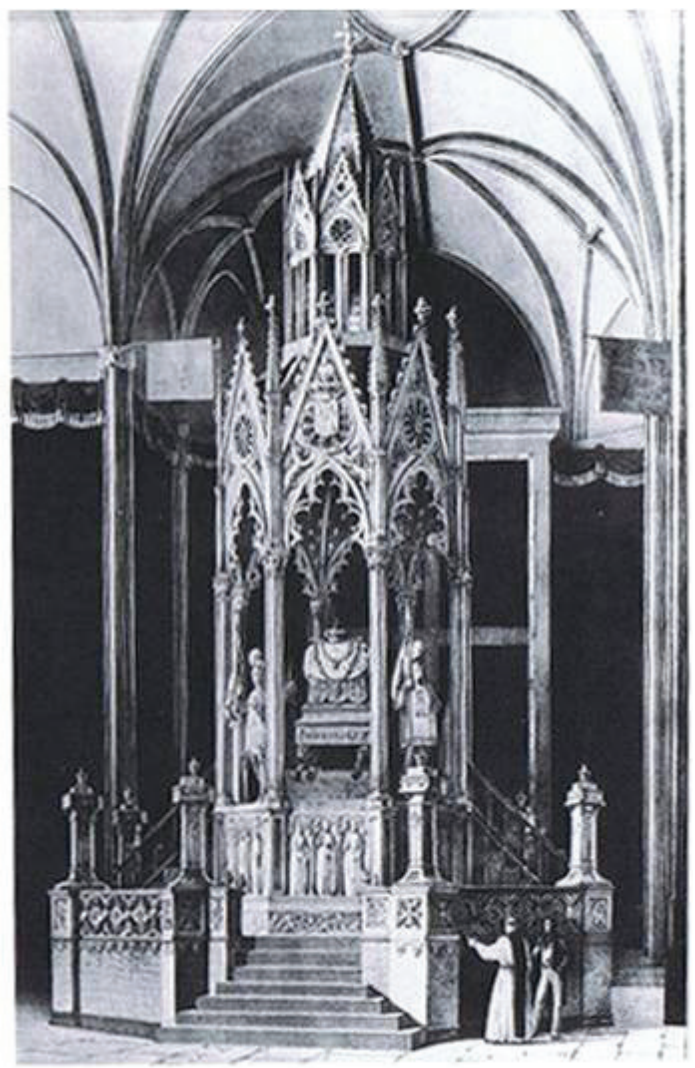

Fig. 4. Valentín Cardereda, Traza para el túmulo para las honras cortesanas de Fernando VII. 1834.

\section{El juego iconográfico}

Una vez presentadas las composiciones efímeras que ornaban el interior de los templos y su evolución, es el momento de atender a la vertiente iconográfica. En este sentido, debemos reconocer la inexistencia de una correspondencia entre estética y simbología dentro de estos actos. Con ello queremos decir que, si bien el mensaje simbólico se encaminó hacia los principios de la Ilustración, no así la estética de la ornamentación fúnebre que se mantuvo apegada a fórmulas barrocas. Si el mensaje evoluciona hacia un absolutismo ilustrado, los mentores emplearon como medio de comunicación los mismos modelos iconográficos, emblemas y alegorías, de manera que facilitaban la comprensión de los presupuestos. Los templos mantuvieron el enlutado hasta mediados del siglo XVIII, recorridos por un amplio conjunto de emblemas e inscripciones. A partir de las ceremonias de Felipe V en 1746, el color va a sustituir las telas negras que pendían del interior de las iglesias, pero se mantiene el amplio despliegue de jeroglíficos y alegorías. 
Dado que el último conjunto de emblemas conocido es el de las exequias municipales de Juan V de Portugal (1751), concebido desde preceptos plenamente codificados, debemos considerar que la desaparición de estos elementos se llevó a cabo de forma paulatina a lo largo de las últimas cuatro décadas de la centuria. Desgraciadamente, ignoramos la existencia de los programas simbólicos que se hubiesen podido desarrollar a partir de la segunda mitad del siglo, más allá de los breves datos acerca de las alegorías que se dispusieron en los catafalcos. Por su parte, los conjuntos emblemáticos quedaron reducidos a códigos plenamente codificados, de fácil interpretación y escaso ingenio, más como elemento obligado y decorativo que como creación iconográfica. En 1789, con motivo de las honras en honor de Carlos III, ha desaparecido totalmente la proyección de jeroglíficos tanto en la Corte como en la Villa debido a la denuncia hacia su oscurantismo significativo. No obstante, se mantuvieron las representaciones alegóricas configuradas en base a un conjunto de carácter macabro fuertemente ligado al concepto de la vánitas.

Esta evolución, en cuanto a la configuración de la imagen, tendrá reflejo en los sermones encomiásticos declamados en estos actos, que se apoyaron en el ornato fúnebre para enfatizar su predicación. Esta interrelación, entre la imagen plástica y la oralidad, promovía un ataque a los sentidos, ampliaba el convencimiento y la conmoción del público asistente a estas teatralizaciones de la muerte. No obstante, si en el devenir evolutivo, la retórica literaria de los sermones fúnebres desaparecía buscando un discurso cívico e institucional de mayor claridad, como el declamado con motivo de las exequias municipales del propio Carlos III por Fray Manuel de Espinosa, no ocurría lo mismo con los jeroglíficos ${ }^{25}$. Estos, que venían siendo la plasmación gráfica de estas predicaciones en los templos, se vieron incapaces de reinventarse dentro de la nueva ideología quedando condenados al olvido.

De aquellos desechados emblemas, con su doble vertiente plástica y literaria, resultaba un mensaje de gran conceptualismo únicamente accesible a los iniciados. Sin embargo, en la aplicación de estos elementos a las ceremonias de exequias, se reconoce el uso de motivos convencionales plenamente arraigados en la sociedad del momento. Este hecho es más acuciante durante el siglo XVIII, en el que, como ya han señalado algunos autores, los emblemas habían perdido su vocación significativa, quedando relegados a elementos puramente decorativos ${ }^{26}$. En el siglo de la Razón, son numerosas las voces que se alzan en contra de este simbolismo misterioso. Un ejemplo bastante ilustrativo de esta nueva concepción y que ya reflejó Gombrich en su Icones Symbolicae es el de Joseph Addison, que critica el exceso interpretativo a la hora de analizar los reversos de las medallas antiguas, con sus motivos simbólicos y sus lemas, en su Diálogo sobre la utilidad de las medallas Antiguas de $1726^{27}$. Y

25 ESPINOSA, Fray Manuel de, Oración fúnebre, que en las solemnes exequias que hizo la muy noble, muy leal, imperial y coronada villa de Madrid... a la dulce memoria de su difunto rey el señor D. Carlos III, Madrid, Imprenta de la viuda de Ibarra, 1789.

26 GÁLLEGO, Julián, "Aspectos emblemáticos en las reales exequias españolas de la Casa de Austria", en Goya, $\mathrm{n}^{\circ}$ 187-188, 1985, pp. 120-125. REVILLA, Federico, "Ideología dieciochesca en el arte efímero", en Quince cuestiones de historia psicosocial del arte, Barcelona, Editorial R. M., 1978.

27 GOMBRICH, Ernest H., Imágenes Simbólicas: Estudios sobre el arte del Renacimiento, vol. 2, Madrid, Debate, 2005, pp. 123-195. 
es que en esta época donde las Academias rigen la creación artística, la búsqueda platónica de la idea en las representaciones se revistió de un racionalismo aristotélico, desdeñando el carácter genérico de los juegos alegóricos y emblemáticos. Pero si el Neoclasicismo propugnaba una vuelta al Mundo Antiguo, desdeñar la metáfora alegórica y emblemática en su corpus creativo no era sino un fallo interpretativo. Y es que si pretendieron revitalizar los mitos griegos en su arte, no contaron con los ya referidos difusos límites que éstos tenían con la interpretación hermenéutica.

\section{La recepción del mensaje}

Una vez presentados los aspectos artísticos y simbólicos de estos actos, atenderemos a la recepción de estas ceremonias por la Corte y Villa de Madrid. Si la Corte utilizó estas celebraciones como método de legitimación de la nueva casa reinante instaurada con Felipe V, la Villa buscó, en la conmemoración de estas honras, mostrar su magnificencia y su adhesión a la dinastía borbónica. En cuanto a la evolución de su interacción con el público, debemos atender a tres estadios fundamentales paralelos a los cambios sufridos por la imagen del rey. Retrotrayéndonos al siglo XVII, la monarquía impulsaba fastuosas ceremonias públicas empleadas como codificación de la continuidad dinástica. Estas ceremonias buscaban una amplia repercusión, tanto en el ámbito nacional, como internacional. Para ello, debemos atender a las ricas Relaciones de Exequias publicadas en este momento, con un gran desarrollo de las ilustraciones y del ornato plástico. El fin último de estos libros tenía un enfoque comercial, ya que la importancia con que la contaban estos actos crearon una alta demanda de este tipo de narraciones que recogían todo el aparato de etiqueta y artístico de los funerales.

Durante el siglo XVIII se continúan publicando las Relaciones de Exequias. No obstante, desde el punto de vista de su dimensión artística se ha reducido potencialmente la inclusión de ilustraciones. La edición de las relaciones en este periodo era de carácter privado, lo que explica la austeridad de las mismas, contrario al enfoque comercial pretendido por las obras de la centuria precedente. Finalmente, a finales del siglo XVIII, con la maquinaria del despotismo ilustrado en marcha, las relaciones de exequias se convierte meros folletines informativos que daban cuenta de la ceremonia, abandonando la retórica barroca de la centuria anterior.

En cuanto a la relación entre estética y mensaje, debemos considerar la existencia de dos niveles de comunicación. El primero, de carácter iniciático, está vinculado con los asistentes a la ceremonia propiamente dicha, capacitados intelectualmente para comprender el desarrollo iconológico de la plástica y su vinculación con el mensaje. En un segundo lugar, existe un mensaje más precario, alejado de intelectualismos, dirigido al pueblo incapaz de comprender los entresijos de la retórica plástica. Este segundo ejercicio de comunicación podríamos denominarlo sentimental por oposición al intelectual. En el siglo XVII y durante la primera mitad del siglo XVIII, se van a promocionar paralelamente ambos modelos de comunicación. Con el auge del barroco más ornamental, el convencimiento de las masas se amplifica a través de la decoración efímera, que ornaba el interior y el exterior de los templos. Estos escenarios, ricamente enlutados, 
podrían ser visitados por el pueblo, que se conmovía y conmocionaba a la vista de los dorados, las hachas humeantes, las estructuras efimeras y las pinturas pendientes de los muros de las naves. No obstante, el pueblo llano estaba alejado del segundo nivel de comprensión, cuyo cénit lo encontramos en la predicación de los sermones, donde se une la plástica con la oralidad siguiendo el hilo argumentativo de la ceremonia, y al que únicamente tenían acceso los grupos de poder de la sociedad del momento. En este sentido, el pueblo llano permanecía conmovido, sentimentalmente afectado, pero sin posibilidad de acceder a una reflexión más profunda.

Con la irrupción del despotismo ilustrado, los pocos ejemplos que conocemos rompen con la dualidad, centrándose en los mensajes más clarificados y didácticos. Desaparece la afectación y el sentimentalismo. En paralelo con la idea de todo para el pueblo pero sin el pueblo, desechan la exuberancia plástica, que capacitaba a la ciudadanía para acercarse al mensaje. Este hecho es consecuencia de la privatización de estos actos y la inoperancia de su mensaje de interregno, dentro de las nuevas estructuras ministeriales del gobierno.

No obstante, un nuevo giro significativo se produce durante el siglo XIX, con el auge del romanticismo y el retorno a la expresión sentimental. El poder ve en estos actos un método de aglutinar al pueblo y convencerlos mediante la conmoción, alejándose, en parte, del intelectualismo de la época anterior. Su construcción va a estar vinculada al incipiente militarismo protocolario y a la configuración heroica y triunfalista de la figura del gobernante. Otro de los aspectos que debemos resaltar es cómo el ceremonial pasa a convertirse en un acto público. Para ello, la ceremonia se va a localizar en iglesias que permitieran alojar a una mayor cantidad de asistentes, como San Francisco el Grande o San Isidro el Real. Estos funerales simbólicos se multiplican haciéndose potestativos para conmemorar el fallecimiento de los Héroes de la nación, aunque son exequias de indudable carácter militar cuya etiqueta se alejaba de los acontecimientos regios. En este sentido, en 1808 tendrán lugar los actos para honrar a las víctimas del 2 de mayo en la iglesia de los Carmelitas Descalzos, a la que se le dotó del acostumbrado túmulo. No obstante, las autoridades deciden repetir los actos el 2 de mayo de 1814 pero, en este caso, no pareció suficiente el simulacro de tumba, por lo que se llevó a cabo la exhumación de los cuerpos de Daoíz y Velarde ${ }^{28}$. Por lo tanto, podemos concluir afirmando que, durante el siglo XIX, se produce una revitalización de las exequias, pero, como en gran parte de los neos, que tienen lugar durante el periodo, estas han quedado definitivamente desvirtuadas ante la incipiente exaltación nacionalista.

28 VARELA, Javier, La muerte del rey: El ceremonial funerario de la monarquía española, 1500-1885, Madrid, Turner, 1990, p. 163 y ss. 